\title{
Polymer-Oxide Composites: Toward New Optical Materials
}

\author{
S.G. NEDILKO* \\ Taras Shevchenko National University of Kyiv, 64/13 Volodymyrska Str., 01601 Kyiv, Ukraine
}

\begin{abstract}
Brief summary concerning properties of the polymer matrix incorporated with inorganic, e.g. oxide particles, micro/nanocomposites and opportunity to use these composites as optical materials for modern optics and optoelectronic devices is presented in the work. Structure and morphology of the several sets of the new polymer micro/nanocomposites based on the microcrystalline cellulose incorporated with micro/nanoparticle of various oxides $\left(\mathrm{NaNO}_{2}, \mathrm{La}_{1-x} \mathrm{Sm}_{x} \mathrm{VO}_{4}, \mathrm{La}_{1-x} \mathrm{Eu}_{x} \mathrm{VO}_{4}\right.$ and $\left.\mathrm{K}_{2} \mathrm{Eu}\left(\mathrm{PO}_{4}\right)\left(\mathrm{MoO}_{4}\right)\right)$, were prepared by "dry" and "wet" cool pressing procedure. Morphology of these composites was described as ensemble of cellulose plates and located gains of the oxide particles. Temperature dependences of complex dielectric permittivity and luminescence properties of the composites were studied. Temperature and electromagnetic field frequency dependences of the dielectric permittivity revealed influence of oxide particles on the characteristics of the microcrystalline cellulose. Both wide band (matrix emission) and narrow lines (RE ions emission) of visible luminescence (350-750 nm range) of the composites is excited in the range $250-550 \mathrm{~nm}$. The luminescence characteristics displayed effect of cellulose on the electronic system of the $\mathrm{Sm}^{3+}$ and $\mathrm{Eu}^{3+}$ ions and effect of oxide particles on the cellulose matrix was shown, too. Spectral characteristics and high intensity of luminescence showed perspectives of studied composites to be used as light converters in LED and elsewhere as optics luminescent materials.
\end{abstract}

DOI: 10.12693/APhysPolA.133.829

PACS/topics: 77.22.Ch, 78.55.-m, 78.66.Sq

\section{Introduction}

As the volume of this paper is very limited, we would like to direct the readers to well known reviews where the main features, current status and recent developments in the field of polymer matrix micro/nanocomposites are available [1-5]. Here, in Sect. 1, we provide only some definitions and short descriptions related with the object and aim of the under study. First, it should be emphasized that in this work we deal only with micro- or nanocomposites. These notations mean that one or more of their components are of sizes in nano- (up to $200 \mathrm{~nm}$ ) and/or microscale ranges (up to $200 \mu \mathrm{m}$ [6]. It is known that properties of the super small particles change when their size is lesser than so-called "critical size". It is of $50 \mathrm{~nm}$ when refractive index changes arise or $100 \mathrm{~nm}$ when electromagnetic phenomena changes, strengthening and toughening occur or hardness and plasticity are modified [7]. So, if we believe to find manifestation of processes actual in optics, we have to operate with materials containing components of size smaller than $100 \mathrm{~nm}$.

Besides, it is important to note when the particles sizes are of nanosized scale, the role of interfaces interactions become significant that allows enhancement of the composite properties. In the most experimental cases we dealt with mixture of micro- and nanosized components of the composites. Therefore, it could be better to denote them as micro/nanocomposites, we suppose.

Micro/nanocomposite materials can be classified, according to their matrix materials, in three different types: ceramic matrix micro/nanocomposites (CMM/NC),

*e-mail: SNedilko@univ.kiev.ua metal matrix micro/nanocomposites (MMM/NC), and polymer matrix micro/nanocomposites (PMM/NC) [1]. We will be in touch here only with the last ones. The $\mathrm{PMM} / \mathrm{NC}$ are of wide applications due to their higher developed level, specific or sometimes unique properties and characteristics if compared to metal and ceramic composites. Thus, various types of polymer-based micro/nanocomposites containing dielectric or semiconductor nanoparticles have already been developed for specific applications. As for polymers themselves, they are widely used in industry and technology due to their easy production, light weight, and ductile nature as well. However, they possess some disadvantages such as low modulus and strength compared to metals and ceramics. That is why, adding fibres, whiskers, or particles into polymer matrix is an approach to effectively enchance mechanical and other polymer's properties. To do it, various polymers have been filled with some inorganic compounds in order to increase heat and impact resistance, mechanical strength, or to modify their electrical conductivity or permeability to oxygen and water molecules [8]. Some metal or ceramic reinforcements opened the way to add new magnetic, electronic, optical or catalytic properties possessed to inorganic, e.g. metal and oxide nanoparticles. Incorporation of these additives allowed improvement of the polymer characteristics simultaneously keeping their lightweight and ductile nature $[2,9,10]$.

The first aim of this work is to provide brief summary about morphology, structure and optical properties of the $\mathrm{PMM} / \mathrm{NC}$ incorporated with inorganic, particularly oxide, compounds which makes them attractive for modern devices, primarily optical ones. We will compare some of these data with ones obtained about PMM/NC made by us. Then, we will take a closer look at the original data concerning own composites, namely, composites made on 
the basis of well-known, but promising in the future polymer, which is cellulose.

\section{Polymer matrix micro/nanocomposites embedded with inorganic oxides as optical materials}

The wide set of polymers are suitable to be used as matrix components of the PMM/NC, e.g. vinyl polymers, condensation polymers, polyolefin, and so on. As for the fillers, various inorganic crystalline compounds have been used. Those were $\mathrm{SiO}_{2}, \mathrm{TiO}_{2}$, other simple metal oxides, but layered silicates were of the most attractive $[10,11]$. No doubts, they are most suitable just due to low particle sizes, peculiarities of surface structure, morphology, and well known chemistry of their intercalation $[11,12]$. Details of the procedures of the polymer matrix composites fabrication are the same either for micro either for nanocomposites and description of these techniques can be found in [13-18] or elsewhere. The most important ones are the next: intercalation of the polymer or pre-polymer from solution, in situ intercalative polymerization, in situ polymerization, template synthesis, melt intercalation, direct mixture of polymer and fillers, and sol-gel process. It seems, the last four of them are more suitable for preparation of the $\mathrm{PMM} / \mathrm{NC}$ incorporated with oxide particles, e.g. with $\mathrm{TiO}_{2}, \mathrm{SiO}_{2}$, $\mathrm{Fe}_{2} \mathrm{O}_{3} ; \mathrm{AgNO}_{3}, \mathrm{NiSO}_{4}$, and $\mathrm{CuSO}_{4}$. Despite of well elaborated different procedures of the $\mathrm{PMM} / \mathrm{NC}$ preparation there are many factors whose influence on the made products is unforeseen, especially if they deal with new combination "matrix-oxide". Those can be size, morphology of the particles, their optimal concentration and distribution over the sample volume and surface. Therefore, composites made by new methods have to be comprehensively investigated using both experimental and theoretical approaches and their mechanical, thermal, electrical and optical characteristics have to be evaluated as well.

Micro/nanosized components of the $\mathrm{PMM} / \mathrm{NC}$ usually are in the form of particles, whiskers, fibers, nanotubes, etc. They are classified according to their dimensions [19]. When all three dimensions are of the same micro- or nanoscale range, they are called as isodimensional particles [19]. The second kind is that constructed from the units that possess two dimensions of the same scale and third dimension is larger. (The carbon nanotubes and cellulose whiskers are the patterns of this type.) The third type is characterized by only one dimension in the micro/nanometer range. In this case, the filler has a view of sheet of one to a few mi$\mathrm{cro} / \mathrm{nm}$ thick and hundreds to thousands micro/nm long. $\mathrm{PMM} / \mathrm{NC}$ made on the base of such type fillers are called as polymer-layered micro/nanocomposites [19, 20].

Really, it is difficult to perform composites of perfect structure e.g., like to polyester $/ \mathrm{TiO}_{2}$ [14]. The authors noted that up to the $\mathrm{TiO}_{2}$ concentration 3 vol. $\%$ the samples showed excellent dispersion of the particles. If the concentration was 4 vol.\% a considerable agglomeration took place (see Fig. 1a). The similar is also true for the $\mathrm{PMM} / \mathrm{NC}-\mathrm{K}_{2} \mathrm{Eu}\left(\mathrm{PO}_{4}\right)\left(\mathrm{MoO}_{4}\right)$ made by us. A lot of $\mathrm{K}_{2} \mathrm{Eu}\left(\mathrm{PO}_{4}\right)\left(\mathrm{MoO}_{4}\right)$ rod-like particles of sizes near 20-30 nm covers the surface of the polymer matrix. At the same time, their large agglomerates of lateral sizes near 1-2 $\mu \mathrm{m}$ and up to $400 \mathrm{~nm}$ pierce through composite surface (Fig. 1b). Thus, these samples, in fact, were micro/nanocomposites. Owing to luminescence properties of such composites, it was possible to illustrate their heterogeneous distribution in significant limits of the sample (Fig. 1c,d).
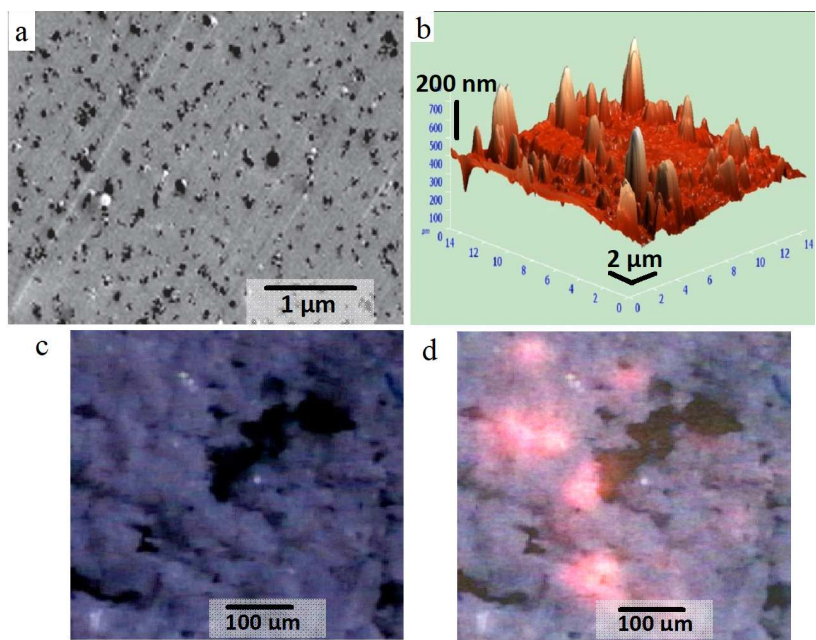

Fig. 1. SEM [1] (a), AFM (b) and optical microscopy images of the polymer based composites containing $\mathrm{TiO}_{2}$ (a) and $\mathrm{K}_{2} \mathrm{Eu}\left(\mathrm{PO}_{4}\right)\left(\mathrm{MoO}_{4}\right)(\mathrm{b})-(\mathrm{d})$ oxides. The image (c) was taken under incident white scattered light. The image (d) was taken under incident violet $\left(\lambda_{e x}=405 \mathrm{~nm}\right)$ laser radiation.

Many properties of $\mathrm{PMM} / \mathrm{NC}$ systems are directly related to their structure. We see manifestation of those relation, e.g. in the luminescence properties of the poly(styrene-alt-maleic anhydride) (PSM) embedded with CdSe nanocrystals. The composite emits luminescence light in emission band peaked at $540 \mathrm{~nm}$. As this type of near band edge luminescence is typical for surfacepassivated nanoparticles, the authors concluded that the structure of the nanoparticles surface is modified by PSM molecules that results in enhancement of luminescence properties [21, 22].

The PMM/NC of layered structure have attracted great interest as they were able to reveal new or improved properties, if compared with starting polymers [23].

Despite of a number of the PMM/NC embedded with inorganic was made, was studied and then they have been used in practice applications, a few works were performed in the field of optics of PMM/NC containing inorganic oxides (see e.g. [24]). It seems undeserved, since firstly oxide compounds have become highly sought after in modern optical devices, and secondly, due to the mutual influence of the micro/nanosized components of the matrix and filler, the optical properties of PMM/NC can 
be substantially modified, comparatively with properties of starting materials.

As for the first statement, one can point out the very well-known example of the polymer-oxide composites use. This is a photoluminescence coating (PLC) of UV or blue LEDs for white LEDs creation on their base. Indeed, it is common knowledge that most commercially attractive WLEDs contain the PLC made on the base of yttrium aluminum garnet (YAG) doped with cerium, $\mathrm{Y}_{3} \mathrm{Al}_{5} \mathrm{O}_{12}: \mathrm{Ce}^{3+}$ (YAG:Ce), dispersed in polymer (silicone) matrix $[25,26]$. Similarly, polymer matrix (polymethylmethacrylate or polyvinylacetate, etc.) incorporated with YAG co-doped with $\mathrm{Pr}$ and Yb (YAG:Pr$\mathrm{Yb}$ ) or with Er and Yb (YAG:Yb-Er), is elaborated as PLC for solar cells [26, 27]. Some examples of the successful creation of the polymer-oxide composites just as optical materials are discussed below. Therefore, let us take a look at the chromium-doped forsterite (Cr$\mathrm{Mg}_{2} \mathrm{SiO}_{4}$ ) in the tribromostyrene/naphthyl methacrylate matrix. This system was directed to the solid-state laser material elaboration, so, polymer matrix was taken with the average refractive index of forsterite (1.652 at $589.3 \mathrm{~nm})$. Optical measurements on the composite films were performed to examine amplification behavior and they showed good results [24]. The $\mathrm{Cr}$ diopside (Cr$\left.\mathrm{CaMgSi}_{2} \mathrm{O}_{6}\right)$ is a material that manifests luminescence in the near-IR range (700-1200 nm). However, a single crystal of this material cannot be prepared due to incongruent melting. Composite system similar to described above, but containing $\mathrm{Cr}-\mathrm{CaMgSi}_{2} \mathrm{O}_{6}$, is an example of how the PMM/NC can be used to improve the process ability and functionality of starting material ( $\mathrm{Cr}$ $\mathrm{CaMgSi}_{2} \mathrm{O}_{6}$ ), which could not be obtained by another way [24]. The set of composites based on polymethylmethacrylate (PMMA) and doped with luminescent particles of the $\mathrm{Pr}^{3+}: \mathrm{LaAlO}_{3} ; \mathrm{Pr}^{3+}: \mathrm{Y}_{2} \mathrm{O}_{3}$, and $\mathrm{Er}^{3+}: \mathrm{Y}_{2} \mathrm{O}_{3}$ were manufactured and characterized [28, 29]. These materials keep the luminescent properties of the original oxide nanopowders. In addition, optimization of the erbium dopant concentration was possible, thus it was found that PMMAEr ${ }^{3+}: \mathrm{Y}_{2} \mathrm{O}_{3}$ composites are available to a limited extent for solid lasers development [29].

Above we examined cases where a polymer was used only as a matrix for fixing an active optic component. Thus, interactions between matrix and filler and their ability to determine the difference between optical properties of the composite and optical properties of matrix and filler was practically ignored. Below, we give a positive example of these issues studying [30]. Therefore, from the physics of scintillations point of view, polymer scintillators possess some advantages such as high operation speed, high light yield, and low cost of their production. However, if compare with inorganic scintillators, the polymer scintillators due to low absorption efficiency have to be of large sizes to register high-energy radiation. Substantial increase of light output can be achieved by the way of embedding into polymer matrix inorganic nanoparticles which are characterized by high atomic numbers $Z$ that promote higher efficiency of hard radiation absorption. Then, excitation energy transfer from nanoparticles to polymer matrix determines larger light yield of composite scintillator (up to 30 times). Thus, such type PMM/NC scintillators combine advantages of both polymer scintillators and scintillators based on inorganic crystals: high light yield and short times scintillation decay, respectively. Described possibility goes from overlapping luminescence spectra of doped with $\mathrm{Pr}^{3+}$ ions $\mathrm{LaPO}_{4}$ nanopaticles with absorption spectrum of polystyrene matrix.

\section{Cellulose matrix micro/nanocomposites embedded with inorganic oxides as new optical materials}

Today there is a strong requirement to replace materials that are widely used both in technology and production, with newer environmentally friendly, harmless to humans and simultaneously cheap materials. The $\mathrm{PMM} / \mathrm{NCs}$, where polymer host is micro/nanocrystalline cellulose and filler is micro/nanosized oxide, belong to mentioned above. These $\mathrm{PMM} / \mathrm{NCs}$ are sustainable and renewable materials and paid great attention in biomedical technologies (membranes and filters, scaffolds, antimicrobial films, pharmaceuticals, drugs delivery, etc. [31-34]) or as adsorbents for toxic chemicals removing [35-37]. Due to their mechanical flexibility they can be useful in manufacturing of the electronic and opto-electronic devices (solar cells, super-capacitors, lithium-ion batteries, "paper" electronics [38-40], luminescence sensors [41-43]). Incorporated with luminescent oxides cellulose based composites have shown their importance as advanced optical materials [44-47]. That is why the second part of this work is devoted to results of our own study of cellulose matrix micro/nanocomposite $(\mathrm{CMM} / \mathrm{NC})$ containing luminescence inorganic oxide micro/nanoparticles.

Cellulose is a biopolymer built on D-glucose units linked to un-branched chains by $\beta$-1,4-glycosidic bonds. The microcrystalline cellulose (MCC) is pure partially depolymerized cellulose. The linear cellulose chains are connected as microfibrils spiralled together in the walls of plant cell. Each microfibril shows a high level of threedimensional internal bonding resulting in the crystalline phase of cellulose. Some part of the microfibrils form amorphous phase of the last one [31-34].

\section{Experimental details}

The set of oxide compounds were used by us as fillers. There were sodium nitrite, $\mathrm{NaNO}_{2}$, cesium nitrate, $\mathrm{CsNO}_{3}$, the doped with active in luminescence samarium or europium three plus ions $\left(\mathrm{Sm}^{3+}\right.$ or $\left.\mathrm{Eu}^{3+}\right)$ lanthanum orthovanadate, $\left.\mathrm{LaVO}_{4}\right)$ and potassium lanthanum phosphate-molybdate, $\mathrm{K}_{2} \mathrm{Eu}\left(\mathrm{PO}_{4}\right)\left(\mathrm{MoO}_{4}\right)$. Described here the CMM/NC were prepared by the "wet" 
(incorporated with $\mathrm{NaNO}_{2}$ and $\mathrm{CsNO}_{3}$ from water solutions) or "dry" cool-pressing methods (all other composites) [44]. The ready for experiments samples were of the discs form of $\approx 10 \mathrm{~mm}$ average diameter. The thickness of the discs was $\approx 1 \mathrm{~mm}$. Amount of oxide was in the range 1-200 $\mathrm{mg}$ for different "dry" samples, while the mass of MCC was $450 \mathrm{mg}$ for each of those samples. Thus, below we denote the sample only as mass and formulae of corresponding oxide, e.g. 10$\mathrm{K}_{2} \mathrm{Eu}\left(\mathrm{PO}_{4}\right)\left(\mathrm{MoO}_{4}\right)$ denotation means that the sample contains $10 \mathrm{mg}$ of $\mathrm{K}_{2} \mathrm{Eu}\left(\mathrm{PO}_{4}\right)\left(\mathrm{MoO}_{4}\right)$ oxide incorporated into $450 \mathrm{mg}$ of MCC. Used oxides could be made by three various procedures: solid state reaction, co-precipitation and sol-gel. We have found recently that luminescence intensity for each oxide depends on the RE ions concentration and on the way of their synthesis $[48,49]$. In fact, we have found that for $\mathrm{LaVO}_{4}$ doped with RE the average size was $1-2 \mu \mathrm{m}$ for solid-state way of the synthesis, $0.2-0.5 \mu \mathrm{m}$ - for the co-precipitation, and $0.1-0.2 \mu \mathrm{m}$ for the sol-gel way. Moreover, luminescence of these oxides made by sol-gel method was near 3 times higher than for the oxides made by co-precipitation and about 10 times higher than for the samples made by solid state synthesis [48]. Therefore, the samples made by the solgel way were selected for experiments with composites. In this way, that oxide procedure and that RE concentration which showed higher PL intensity were selected for composites preparation and further experiments. As for the "wet" samples, an amount of oxide component was determined by its concentration in water solutions. We denote the composites of such type here as $\mathrm{W}-\mathrm{NaNO}_{2}$ and $\mathrm{W}-\mathrm{CsNO}_{3}$. The details both of the oxides synthesis and the samples preparation can be found in $[36,37$, 44, 48, 49].

As we noted in Sect. 2, the morphology, structure and other properties of the $\mathrm{PMM} / \mathrm{NC}$ samples depend on their composition and on the way of the samples preparation. Thus, various characteristics had to be studied, as the samples were made for the first time. This required us to use a variety of experimental methods. Those were scanning electron microscopy (SEM), chemical elements analysis, X-ray diffractometry (XRD), luminescence spectroscopy and dielectric characteristics measurements. Equipment and any other details of experimental study can be found also in $[36,37,44,48,49]$.

\section{Results and discussion}

\subsection{Morphology and structure}

The samples surfaces were scanned using electron microscopy instruments. Figure 2 shows the typical SEM image (the sample $100-\mathrm{K}_{2} \mathrm{Eu}\left(\mathrm{PO}_{4}\right)\left(\mathrm{MoO}_{4}\right)$ was taken as example). A lot of tightly packed grains of 5-10 $\mu \mathrm{m}$ of size can be seen over there. Usually, they packed into large plates of $\approx 20-50 \mu \mathrm{m}$ of size. Some crannies are also seen between the plates (see, e.g., in left part and in the center of Fig. 2). Another shape pieces also are on this image. They look like to different inclusions on the samples surface (see rectangles $\# 3$ and $\# 4$ in Fig. 2 , e.g.). Their sizes are in 10-200 $\mathrm{nm}$ range. Conglomerates of such particles form larger pieces of $2-10 \mu \mathrm{m}$ size. The largest of them is near rectangle $\# 5$ in Fig. 2.

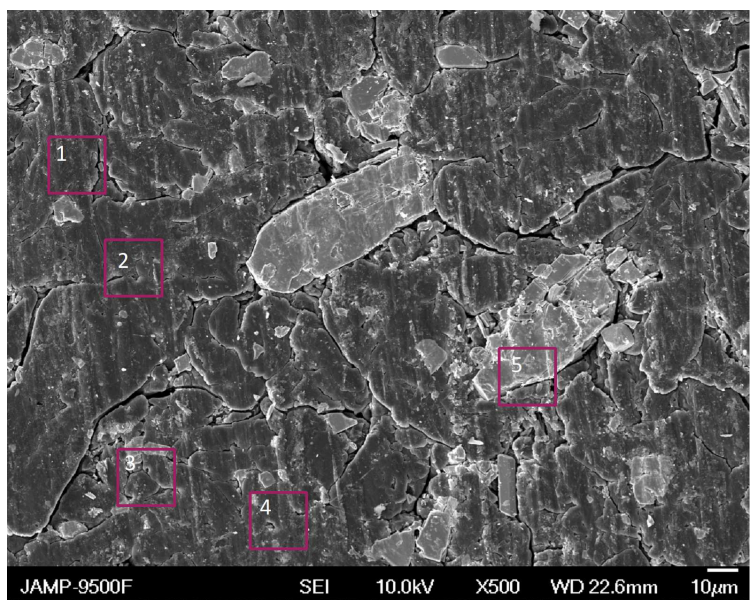

Fig. 2. Typical SEM image of the cellulose based composite (the sample $100-\mathrm{K}_{2} \mathrm{Eu}\left(\mathrm{PO}_{4}\right)\left(\mathrm{MoO}_{4}\right)$. The rectangles show areas where chemical analysis was performed.

\subsection{Chemical elements analysis}

The analysis was made for some zones of the samples when SEM studies were carried out. Those zones are marked by rectangles in Fig. 2. The average content of carbon $(\mathrm{C})$ atoms (the range of its value is $74-76$ at.\% for all of the samples under study) and oxygen $(\mathrm{O})$ atoms (25-23 at.\%) were predominant in zones of the plates (see zones 1 and 2, e.g.), that allowed us to conclude that the plates are blocks of the MCC matrix. The results of analysis also pointed out that mentioned above inclusions (see zones 3, 4, and 5, e.g.) are the areas where the oxide particles were located, as their composition is close to the chemical formulas of corresponding oxides. Average content of the chemical elements for the MCC and some composites in the zones of particles inclusions are accumulated in Table I.

TABLE I

The average values of the chemical elements content in (A) $10-\mathrm{La}_{0.7} \mathrm{Sm}_{0.3} \mathrm{VO}_{4}$, (B) 10-La ${ }_{0.7} \mathrm{Eu}_{0.3} \mathrm{VO}_{4}$, and (C) $100-\mathrm{K}_{2} \mathrm{Eu}\left(\mathrm{PO}_{4}\right)\left(\mathrm{MoO}_{4}\right)$, composites (in at.\%); cellulose crystallinity index $k$, and the value of the reorientation energy barrier $U$ (in $\mathrm{kJ} / \mathrm{mol}$ ).

\begin{tabular}{c|c|c|c|c|c|c|c|c|c|c|c}
\hline \hline Sample & C & K & La & Sm & Eu & V & P & Mo & O & $k$ & $U$ \\
\hline MCC & 65.3 & - & - & - & - & - & - & - & 34.5 & 66 & 75 \\
(A) & 0.3 & - & 11.2 & 5.8 & & 16.9 & - & - & 65.8 & 57 & 62 \\
(A) & 5.2 & - & 10.9 & - & 6.1 & 16.4 & - & - & 61.4 & 57 & 55 \\
(C) & 6.5 & 9.41 & - & - & 6.87 & - & 6.96 & 8.31 & 62.51 & 58 & 54
\end{tabular}

\subsection{XRD analysis}

The XRD patterns of the samples under study showed the set of diffraction peaks related with X-ray scattering 
on the MCC lattice in the range $10-45^{\circ}$ of $2 \theta[45,51,52]$. These relatively wide intensive peaks are located at 16 , 22.5 , and $34.5^{\circ}$ of $2 \theta$. Several features of low intensity also were found as shoulders for all the samples. Others observed XRD peaks are not related with MCC XRD scattering. Intensity of those peaks increases when oxides content increases. Therefore, we concluded that additive peaks are caused by oxide components of composites. It was confirmed by those peaks positions comparison with XRD pattern of the $\mathrm{NaNO}_{2}, \mathrm{CsNO}_{3}$, $\mathrm{La}_{1-x} \mathrm{Sm}_{x} \mathrm{VO}_{4}, \mathrm{La}_{1-x} \mathrm{Eu}_{x} \mathrm{VO}_{4}$, and $\mathrm{K}_{2} \mathrm{Eu}\left(\mathrm{PO}_{4}\right)\left(\mathrm{MoO}_{4}\right)$ compounds [37, 48, 49-53]. Detailed description and analysis of the similar composites XRD patterns can be found in [44].

On the base of the XRD results index of the cellulose crystallinity $(k)$ was calculated for the all studied samples. For this aim the contribution of the amorphous phase $\left(I_{a m}\right)$ to the overall XRD spectrum $\left(I_{\text {cryst }}+I_{a m}\right)$, where $I_{c r}$ is an area under XRD peaks caused crystal phase of cellulose, was extracted. (This procedure had been already previously described in detail [44].) Thus, the crystallinity level was evaluated as a ratio

$$
\kappa=\frac{I_{c r}}{I_{c r}+I_{a m}} .
$$

Calculated $k$ values were found to be near $57-58 \%$ for the composites, while for the un-doped micro/nanocellulose (MCC) this value was higher - 66\% (Table I). Thus, we can note that oxide particles affect the structure and morphology of the MCC host and somewhat destroy its crystal lattice. Undoubtedly, future experiments are needed to clarify a mechanism of this effect. Moreover, described below the results of the MCC and CMM/NC-oxide composites dielectric properties study also revealed that oxide component influence cellulose characteristics.

\subsection{Dielectric properties}

Dependences of the real $\left(\varepsilon^{\prime}\right)$ and imaginary $\left(\varepsilon^{\prime \prime}\right)$ parts of the complex dielectric permittivity $\left(\varepsilon^{*}\right)$ on temperature measured for studied MCC and $\mathrm{CMM} / \mathrm{NC}$ at different frequencies of probing electromagnetic field (EMF) can be seen in Fig. 3. If we compare the dependences taken for composites with ones obtained for un-doped MCC (Fig. 3a,b), it is easy to find that general view of these curves is similar. At the same time, some differences should be noted. First, we see that if an oxide is added, the shape of the $\varepsilon^{\prime}$ and $\varepsilon^{\prime \prime}$ curves changes. In fact, relative intensity of the $\varepsilon^{\prime}$ curves increases in the range $-125-25^{\circ} \mathrm{C}$ and the $\varepsilon^{\prime \prime}$ values increase in the whole temperature range. Especially, it concerns the temperature range $25-125^{\circ} \mathrm{C}$, where the $\varepsilon^{\prime \prime}$ values in the maximum of the curves increase in 4-6 times. We can note that only $\left(\varepsilon^{\prime}, \varepsilon^{\prime \prime}\right)$ values changes occur in the range $25-125^{\circ} \mathrm{C}$, if EMF frequency or oxide content increase and there is no $\left(\varepsilon^{\prime}, \varepsilon^{\prime \prime}\right.$ curves shifts in these temperature range. In contrast, it easy to see that $\varepsilon^{\prime \prime}$ curves in the range $-125-25^{\circ} \mathrm{C}$ shift to the higher temperature side when EMF frequency increases. Therefore, we assume that two kinds of impact of oxide particles on the surface MCC molecular groups take place, and their responses on this influence are different. Obviously, some amount of water molecules, hydroxyl groups and ambient gases had been incorporated into MCC host as associated with the surface of oxide particles. There they bind to molecular groups on the surface of MCC microfibrils that promote increase of the dipole moment (polarizability) of the samples. As results, $\varepsilon^{\prime \prime}$ values increase when oxide is added (please compare Fig. 3b and Fig. 3d,f,h). These changes manifested in the dielectric permittivity behaviour during first heating of the sample in the EMF of lower frequency. Next heating made under action of the higher EMF frequency removes more water and some ambient gases molecules and leads to decrease of the $\left(\varepsilon^{\prime}, \varepsilon^{\prime \prime}\right)$ values. These changes noticeably revealed in the temperature range $25-125^{\circ} \mathrm{C}$.
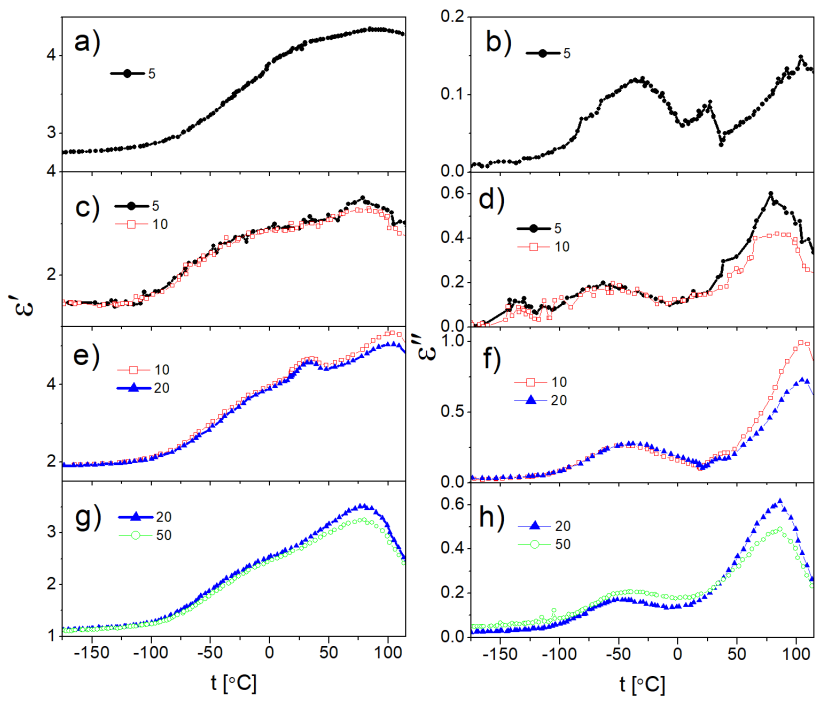

Fig. 3. Dependences on temperature of the real $(\mathrm{a}, \mathrm{c}, \mathrm{e}, \mathrm{g})$ and imaginary $(\mathrm{b}, \mathrm{d}, \mathrm{f}, \mathrm{h})$ parts of dielectric permittivity for undoped cellulose $(\mathrm{a}, \mathrm{b})$ and composites (c)-(h); $10-\mathrm{La}_{0.7} \mathrm{Sm}_{0.3} \mathrm{VO}_{4}$ (c,d), $10-\mathrm{La}_{0.7} \mathrm{Eu}_{0.3} \mathrm{VO}_{4}$ $(\mathrm{e}, \mathrm{f})$, and $10-\mathrm{K}_{2} \mathrm{Eu}\left(\mathrm{PO}_{4}\right)\left(\mathrm{MoO}_{4}\right)(\mathrm{g}, \mathrm{h})$. Used frequencies used at experiments (in $\mathrm{kHz}$ ) are marked in the figure.

Temperature and frequency behaviour of the $\left(\varepsilon^{\prime}, \varepsilon^{\prime \prime}\right)$ values in low temperature range, $-125-25^{\circ} \mathrm{C}$, are typical for over-barrier reorientations of molecules between their two equilibrium positions in solid state. We assume that found by us reorientations occur as thermal transitions (from $t g$ to $t t$ conformation) of methyl groups located on the surface of the MCC microfibrils.

It is of interest to note that behaviour of the $\left(\varepsilon^{\prime}, \varepsilon^{\prime \prime}\right)$ in the whole temperature range is similar to temperature behaviour reported in [54-56] about viscoelastic characteristics (storage modulus and tang $\delta$ ) of hydroxypropyl cellulose composites reinforced with cellulose nanofibers. The authors related measured by them dependences with two types of relaxations both involving large-scale molecular motions [54] and changes of the crystalline, amorphous and intermediate order phases amount [54-56]. 
We suppose that similar processes occur in the case of the $\mathrm{CMM} / \mathrm{NC}$ which are under our study. Moreover, we think that relaxations which are realized in the low temperature range, $-125-25^{\circ} \mathrm{C}$, promote to phase transformations of mentioned above type, which take place in the higher temperature range $25-125^{\circ} \mathrm{C}$.

Fitting of experimental $\varepsilon^{\prime}(T, f)$ curves with corresponding theoretical dependences in the Debye approximation was performed for the temperature range -125 $25^{\circ} \mathrm{C}$ (Fig. 3) and the energy barriers between two equilibrium positions, $U$, have been evaluated. Corresponding values are accumulated in Table I. It is easy to see that $U$ values show significant influence of the oxide component on the relaxation conditions in cellulose matrix that confirm the role of the microfibrils surface molecular groups.

It is clear that these issues are far from their total understanding that is why further study in this direction has to be performed. Nevertheless, placed below data concerning effect of oxide particles on luminescence properties of studied composites confirm the role of the cellulose-oxide interactions.

\subsection{Luminescent properties}

Photoluminescence (PL) of the MCC and CMM/NCoxide composites is excited in the wide spectral range from UV to yellow light (250-570 nm) (Figs. 4 and 5). The PL spectra consist of wide band that extends from 350 up to $750 \mathrm{~nm}$ (Fig. 4, curves 1-5). Besides, the sets of relatively narrow lines are in the spectra of the composites embedded with oxides doped with $\mathrm{RE}$ ions $\mathrm{Sm}^{3+}$ (Fig. 4, curve 6) and $\mathrm{Eu}^{3+}$ (Fig. 4, curves 7 and 8). Relative intensities of the wide band and narrow lines depend on the sample composition. Therefore, some traces of the fine structure can be found in the spectral ranges 470-750 nm and 560-580, 580-615 and 645-665 $\mathrm{nm}$ of the PL spectra of $\mathrm{W}-\mathrm{NaNO}_{2}$ (Fig. 4, curve 3) and 10$\mathrm{La}_{0.7} \mathrm{Sm}_{0.3} \mathrm{VO}_{4}$ composites (Fig. 4, curve 5), respectively. If oxide amount is higher (100-La ${ }_{0.7} \mathrm{Sm}_{0.3} \mathrm{VO}_{4}$ composite) the lines are significantly enhanced (Fig. 4, curve 6).

The shape and peak position $\left(\lambda_{\max }\right)$ of the wide $\mathrm{PL}$ band also depend on the sample preheating and on the sample composition. Taking into account previously found results $[36,37,44]$ we can conclude that the wide band at least consists of four strongly superposed components with $\lambda_{\max }$ near $420-430,505,565$, and $600 \mathrm{~nm}$. Contributions of these components to the total spectra changes in different way after MCC heating (Fig. 4, curve 2) or if oxide is embedded into MCC. The former leads to the short wavelength side domination in the spectra (Fig. 4, curve 2). As for the last, as a rule, short wavelength luminescence components dominate in the spectra of composites, however, middle components become predominant when amount of oxide increases (Fig. 4, curve 6).

The spectra of the wide band PL excitation similarly to emission spectra showed complex structure (Fig. 5). As for starting MCC sample, excitation spectra consist

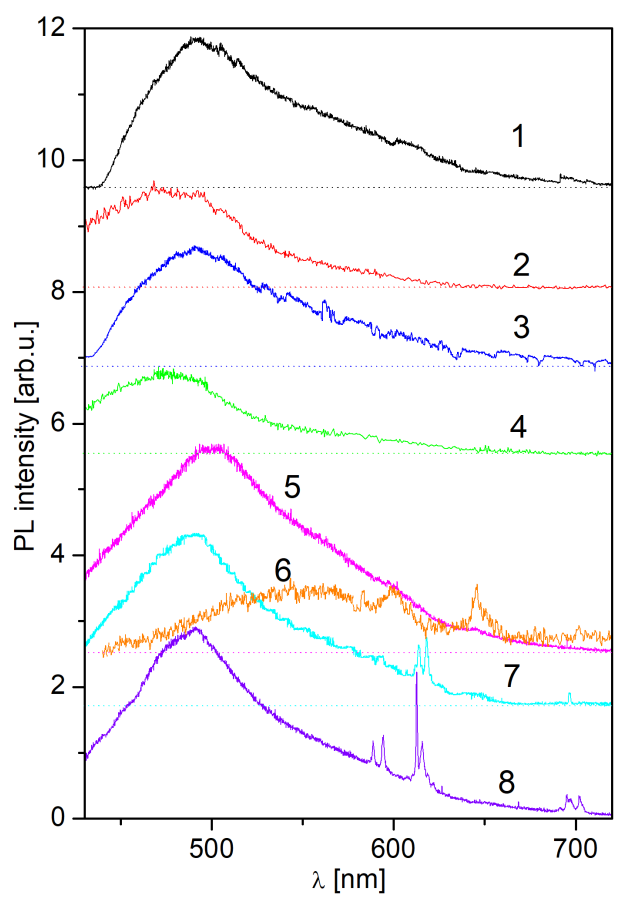

Fig. 4. The PL spectra of starting cellulose MCC (1), MCC heated to $T=130^{\circ} \mathrm{C}(2)$, and composites: $\mathrm{W}-\mathrm{NaNO}_{2}$ (3), W-CsNO 3 (4), 10-La0.7 $\mathrm{Sm}_{0.3} \mathrm{VO}_{4}$ (5), 100-La ${ }_{0.7} \mathrm{Sm}_{0.3} \mathrm{VO}_{4}$ (6), 10-La ${ }_{0.7} \mathrm{Eu}_{0.3} \mathrm{VO}_{4}$ (7), and 10$\mathrm{K}_{2} \mathrm{Eu}\left(\mathrm{PO}_{4}\right)\left(\mathrm{MoO}_{4}\right)(8) ; \lambda_{e x}=405 \mathrm{~nm}, T=300 \mathrm{~K}$.

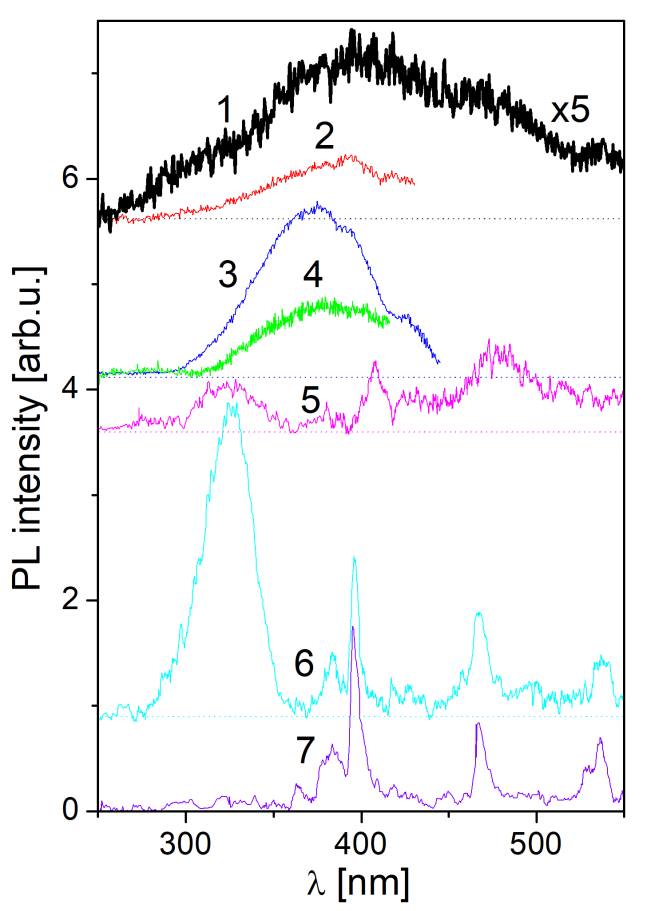

Fig. 5. The PL excitation spectra of the MCC (1, 2) and composites: $\mathrm{W}-\mathrm{NaNO}_{2}$ (3), $\mathrm{W}-\mathrm{CsNO}_{3}$ (4), 100-La ${ }_{0.7} \mathrm{Sm}_{0.3} \mathrm{VO}_{4}$ (5), 1- $\mathrm{La}_{0.7} \mathrm{Eu}_{0.3} \mathrm{VO}_{4}$ (6) and 10$\mathrm{K}_{2} \mathrm{Eu}\left(\mathrm{PO}_{4}\right)\left(\mathrm{MoO}_{4}\right)(7) ; \lambda_{\text {reg }}=460(2,3), 475(4), 580$ (1), $612.5(7), 613.3$ (6) and $644.6 \mathrm{~nm}(5) ; T=300 \mathrm{~K}$. 
of several overlapping bands lying in the ranges $\approx 250$ 350, 300-425, 350-475 and 425-525 nm. Excitation spectra change if wavelength of the $\mathrm{PL}$ registration $\left(\lambda_{\text {reg }}\right)$ changes. Thus, short wavelength band in excitation (250-350 nm) vanishes if $\lambda_{\text {reg }}$ changes from 580 to $460 \mathrm{~nm}$ (Fig. 5, curves 1,2). The same was observed for excitation of luminescence of the $\mathrm{W}-\mathrm{NaNO}_{2}$ and $\mathrm{W}-\mathrm{CsNO}_{3}$ composites. We see that only $300-450 \mathrm{~nm}$ range of excitation is actual while others ones diminished (Fig. 5, curves 3,4$)$.

Described data are similar to ones measured by us or elsewhere for the MCC, another "cellulose-oxide" composites or various cellulose based materials [39, 42-44, $37,38,45]$. Therefore, we are able to conclude that wide PL band and related components in the excitation spectra are caused by luminescence processes in MCC host. As for origin of this luminescence we can briefly emphasize that noted above luminescence features show presence of several luminescence sources. Those are several types of molecular fluorophores belonging to the host [4143]. It is not completely clarified question about direct role of concrete type of MCC molecular constituents or its derivatives (e.g., carbonyl groups), but the role of some molecular radicals located on the surface of cellulose microfibrils had been already emphasized. For example, hydroxyl groups located on the surface promoted organic molecules adsorption that results in enhancement of the PL $[42,43]$. In relation with noted above, we point here that situation with luminescence excitation in the cases of the $\mathrm{W}-\mathrm{NaNO}_{2}$ (Fig. 5, curve 3) and $\mathrm{W}-\mathrm{CsNO}_{3}$ (Fig. 5, curve 4) differ radically. In fact, the $\mathrm{NaNO}_{2}$ oxide can itself contribute to the luminescence of composite, while the $\mathrm{CsNO}_{3}$ oxide did not show luminescence at any conditions [57-60]. It means that excitation spectrum 3 in Fig. 5 could reflect simultaneously excitation of both the $\mathrm{NaNO}_{2}$ particles and MCC matrix, while the spectrum 4 in Fig. 5 just reflects excitation of the cellulose matrix only. Nevertheless, there is similarity of these excitation spectra that indicates excitation energy exchange between cellulose matrix and oxide particles. Our results also revealed correspondence between components in luminescence and excitation spectra and confirms that several origins contribute to the luminescence of cellulose matrix. Namely, we can state that the shortwave side of the MCC luminescence is excited in the bands ranging from 300 to $450 \mathrm{~nm}$. We state also that both heating and oxide particles action on these sources is selective and different, which may be due to the features of molecular relaxations and due to features of the molecular anions of oxides (nitrite, $\mathrm{NO}_{2}^{-}$, nitrate, $\mathrm{NO}_{3}^{-}$, vanadate, $\mathrm{VO}_{4}^{3-}$, phosphate, $\mathrm{PO}_{4}^{3-}$ or molybdate, $\mathrm{MoO}_{4}^{-}$) binding with molecular groups on the surface of cellulose microfibrils.

When the PL is registered near the narrow PL lines, new details of the excitation spectra have been measured (Fig. 5, curves 5-7). No doubts, these additives, as well as narrow lines in the PL spectra are related with absorption and radiation transitions in the $f^{n}$-shells of $\mathrm{Sm}^{3+}$ or $\mathrm{Eu}^{3+}$ ions and $\mathrm{O}^{2-} \rightarrow \mathrm{RE}^{3+}$ charge transfer transitions in oxide component of the composites. Really, the positions of these groups of lines, their shapes and their intensity coincide with excitation and luminescence data for corresponding "free" powder oxides taken by us recently [48, 49]. Change of the shape and decrease of MCC host PL intensity, when content of the oxide increases, can be related with influence of the oxide particles on the morphology and dynamics of various cellulose molecular groups located on the microfibrils surface. It is worth to note that distributions of intensity of the $\mathrm{Sm}^{3+}$ and $\mathrm{Eu}^{3+}$ ions PL lines differ from ones corresponding to "free" oxide powders $[48,49]$. We have known that these $\mathrm{RE}^{3+}$ ions locate in the volume and on the surface of used particles, too $[48,49]$. Positions of the lines in the PL and excitation spectra of the $\mathrm{Sm}^{3+}$ and $\mathrm{Eu}^{3+}$ ions for noted "at surface" and "in volume" types of ions are different. Obviously, "at surface" ions, in the first place, have been sensitive to the influence of the cellulose surface molecular groups. Thus, interaction between surface molecular groups of cellulose and surface molecular groups of oxide determine peculiarities of luminescence and dielectric behavior of the studied composites also.

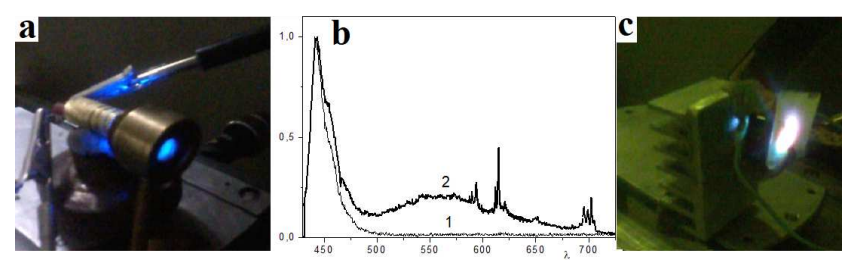

Fig. 6. (a) The view on the eye, of the blue LED emission, (b) normalized emission spectrum of the blue LED (1) and the emission spectrum of the system (2), (c) view on the eye, of the "blue LED + 100$\mathrm{K}_{2} \mathrm{Eu}\left(\mathrm{PO}_{4}\right)\left(\mathrm{MoO}_{4}\right)$ composite" system emission.

Measured luminescence characteristics make studied composites suitable for transformation of the UV, violet or blue light to the emission of wide spectral range at longer wavelengths. If to combine emission of the LED as excitation light and the luminescence of studied composite, e.g., $100-\mathrm{K}_{2} \mathrm{Eu}\left(\mathrm{PO}_{4}\right)\left(\mathrm{MoO}_{4}\right)$, we will take emission of complex system "blue LED $+100-\mathrm{K}_{2} \mathrm{Eu}\left(\mathrm{PO}_{4}\right)\left(\mathrm{MoO}_{4}\right)$ composite" (Fig. 6b). Spectrum of this system emission extends from 450 up to $750 \mathrm{~nm}$ and it is a combination of wide band LED blue emission, wide band green-yellow emission of the cellulose host, and red emission of the oxide. As result, we obtained white on the eye emission of such modeling device (Fig. 6c). View on the eye of the starting blue LED emission is given in Fig. 6a for comparison.

\section{Conclusions}

Presented in the work short review about properties of the polymer incorporated with inorganic, particularly oxide particles, micro/nanocomposites showed their perceptiveness to be used as materials for modern optics and opto-electronic devices. 
The sets of the new polymer micro/nanocomposites based on the microcrystalline cellulose host and embedded with micro/nanoparticle of various luminescent complex oxides $\left(\mathrm{NaNO}_{2}, \mathrm{La}_{1-x} \mathrm{Sm}_{x} \mathrm{VO}_{4}, \mathrm{La}_{1-x} \mathrm{Eu}_{x} \mathrm{VO}_{4}\right.$ and $\left.\mathrm{K}_{2} \mathrm{Eu}\left(\mathrm{PO}_{4}\right)\left(\mathrm{MoO}_{4}\right)\right)$, were made by "dry" and "wet" coolpressing procedure. Their morphology can be described as ensemble of cellulose plates and located between them or inside them oxide particles.

Dielectric and luminescence properties of composites were studied and their characteristics were evaluated. It was found that studied micro/nanocomposites are not ordinary mechanical mixture of the microcrystalline cellulose and oxide compound. The luminescence characteristics display effect of cellulose on the electron-vibration system of the $\mathrm{Sm}^{3+}$ and $\mathrm{Eu}^{3+}$ ions and, on the other hand, effect of the oxide particles on the microfibrils components of cellulose was shown, too. Dependences of the dielectric permittivity of the composites cellulose host also revealed influence of oxide particles on the characteristics of the microcrystalline cellulose.

Both wide band and narrow lines of visible luminescence (350-750 nm range) of the composites is excited in the range 250-550 nm. Spectral characteristics and high intensity of luminescence determine these composites as perspective for creation on their base of luminescent covers for ultraviolet and violet LED with the aim to transform their radiation into white light.

\section{Acknowledgments}

The author is grateful to the leaders of the chemistry groups, Prof. M. Slobodyanyk and Prof. S.A. Nedilko, researchers from these groups, Ass. Prof. K. Terebilenko and senior researcher T. Voitenko, PG student A. Slepets for their work on the synthesis of phosphate-molybdate and vanadate compounds, respectively.

Many thanks to senior researcher O. Alekseyev and Ass. Prof. M. Lazarenko for the study of dielectric properties and analysis of the results.

Thanks for leading engineer M. Nedielko for her work on SEM and optical microscopy.

My thanks to senior researcher O. Chukova, junior researcher V. Chornii, and leading engineer V. Scherbatskii for their work on oxides and composites luminescent properties study.

\section{References}

[1] P.H.C. Camargo, K.G. Satyanarayana, F. Wypych, Mater. Res. 12, 1 (2009)).

[2] J. Jordan, K.I. Jacob, R. Tannenbaum, M.A. Sharaf, I. Jasiuk, Mater. Sci. Eng. A 393, 1 (2005)).

[3] R.A. Vaia, H.D. Wagner, Mater. Today 7, 32 (2004)).

[4] H.S. Nalwa, Handbook of Nanostructured Materials and Technology, Academic Press, New York 2000.

[5] P.M. Ajayan, L. Schadler, P.V. Braun, Nanocomposites Science and Technology, Wiley-VCH, Weinheim 2003.

[6] R. Roy, R.A. Roy, D.M. Roy, Mater. Lett. 4, 323 (1986)).
[7] O. Kamigaito, J. Japan Soc. Powder Metall. 38, 321 (1991).

[8] H. Fischer, Mater. Sci. Eng. C 23, 763 (2003)).

[9] S.A. Zavyalov, A.N. Pivkina, J. Schoonman, Solid State Ion. 147, 415 (2002)).

[10] C.M. Thompson, H.M. Herring, T.S. Gates, J.W. Connel, Composit. Sci. Technol. 63, 1591 (2003)).

[11] M. Alexandre, P. Dubois, Mater. Sci. Eng. 28, 1 (2000)).

[12] M. Ogawa, K. Kuroda, Bull. Chem. Soc. Japan 70, 2593 (1997)).

[13] H.G. Jeon, H.T. Jung, S.W. Lee, S.D. Hudson, Polym. Bull. 41, 107 (1998)).

[14] V.M.F. Evora, A. Shukla, Mater. Sci. Eng. A 361 , $358(2003))$

[15] M.L. Di Lorenzo, M.E. Errico, M. Avella, J. Mater. Sci. 37, 2351 (2002)).

[16] S.S. Park, N. Bernet, S. de La Roche, H.T. Hanh, J. Compos. Mater. 37, 465 (2003)).

[17] A. Dutta, D. Das, M.L. Grilli, E. Di Bartolomeo, E. Traversa, D. Chakravorty, J. Sol-Gel Sci. Technol. 26, 1085 (2003)).

[18] N. Herron, D.L. Thorn, Adv. Mater. 10, 1173 (1998). DOI:10.1002/(SICI)1521-4095(199810)10:15

[19] D. Schmidt, D. Shah, E.P. Giannelis, Curr. Opin. Solid State Mater. Sci. 6, 205 (2002)).

[20] S.S. Ray, M. Okamoto, Progr. Polym. Sci. 28, 1539 (2003)).

[21] S.H. Liu, X.F. Qian, J.Y. Yuan, J. Yin, R. He, Z.K. Zhu, Mater. Res. Bull. 38, 1359 (2003)).

[22] T. Trindade, M.C. Neves, A.M.V. Barros, Scr. Mater. 43, 567 (2000)).

[23] R. Krishnamoorti, R.A. Vaia, E.P. Giannelis, Chem. Mater. 8, 1728 (1996)).

[24] L.L. Beecroft, C.K. Ober, Chem. Mater. 9, 1302 (1997). DOI:10.1021/cm960441a

[25] V. Tucureanu, A. Matei, A.M. Avram, OptoElectron. Rev. 23, 239 (2015)).

[26] E. Klampaftis, D. Rossa, K.R. McIntosh, B.S. Richards, Solar En. Mater. Solar Cells 93 1182 (2009))

[27] P. Ramasamy, P. Manivasakan, J. Kim, RSC Adv. 4, 34873 (2014)).

[28] M. Dudek, A. Jusza, K. Anders, L. Lipińska, J. Rare Earths 29, 1123 (2011)).

[29] K. Anders, A. Jusza, M. Baran, L. Lipińska, R. Piramidowicz, Opt. Mater. 34, 1964 (2012)).

[30] V. Vistovsky, N. Mitina, A. Shapoval, T. Malyy, A. Gektin, T. Konstantinova, A. Voloshinovskii, A. Zaichenko, Opt. Mater. 34, 2066 (2012)).

[31] A. Kumar, Yu.S. Negi, V. Choudhary, N.K. Bhardwaj, J. Mater. Phys. Chem. 2, 1 (2014)).

[32] R.J. Moon, A. Martini, A. Nairn, J. Simonsen, J. Youngblood, Chem. Soc. Rev. 40, 3941 (2011)).

[33] I. Siro, D. Plackett, Cellulose 17, 459 (2010)).

[34] S. Ummartyotin, C. Pechyen, Carbohydr. Polym. 142, 133 (2016)) 
[35] Z. Zhou, Q. Wang, Sens. Actuat. B 173, 833 (2012)).

[36] S. Nedilko, S. Revo, M. Nedielko, T. Avramenko, K. Ivanenko, V. Scherbatskii, Solid State Phenom. 230, 147 (2015)).

[37] S.G. Nedilko, S.L. Revo, V.P. Chornii, V.P. Scherbatskyi, M.S. Nedielko, J. Sens. Sens. Syst. 4, 31 (2015)).

[38] M. Karakawa, M. Chikamatsu, C. Nakamoto, Y. Maeda, S. Kubota, K. Yase, Macromol. Chem. Phys. 208, 2000 (2007)).

[39] S. Yun, S.D. Jang, G.Y. Yun, J.H. Kim, J. Kim, Appl. Phys. Lett. 95, 104102 (2009)).

[40] N. Wang, E. Ding, R. Cheng, Langmuir 24, 5 (2008)).

[41] R.P. Bateh, J.D. Winefordner, Talanta 29, 713 (1982)).

[42] V. Pikulev, S. Loginova, V. Gurtov, Nanoscale Res. Lett. 7, 426 (2012)).

[43] H. Tylli, I. Forsskahl, C. Olkkonen, Cellulose 7, 133 (2000)).

[44] M. Nedielko, S. Hamamda, O. Alekseev, V. Chornii, M. Dashevskii, M. Lazarenko, K. Kovalov, S.G. Nedilko, S. Tkachov, S. Revo, V. Scherbatskyi, Nanoscale Res. Lett. 12, 98 (2017)).

[45] P. Kulpinski, A. Erdman, T. Grzyb, S. Lis, Polym. Composit. 37, 153 (2016). DOI $10.1002 /$ pc. 23166

[46] E. Smiechowicz, P. Kulpinski, B. Niekraszewicz, A. Bacciarelli, Cellulose 18, 975 (2011)).

[47] P. Kulpinski, A. Erdman, M. Namyślak, J.D. Fidelus, Cellulose 19, 1259 (2012))
[48] V. Chornii, O. Chukova, S.G. Nedilko, S.A. Nedilko, T. Voitenko, Phys. Status Solidi C 13, 40 (2016)).

[49] Yu. Hizhnyi, V. Chornii, S. Nedilko, M. Slobodyanik, K. Terebilenko, V. Boyko, O. Gomenyuk, V. Sheludko, Radiat. Measur. 90, 314 (2016)).

[50] C. Driemeier, G.A. Calligaris, J. Appl. Crystallogr. 44, 184 (2011)).

[51] K. Leppeanen, S. Andersson, M. Torkkeli, M. Knaapila, N. Kotelnikova, R. Serimaa, Cellulose 16, 999 (2009)).

[52] W. Laue, M. Thiemann, E. Scheibler, K.W. Wiegand, Ullmann's Encyclopedia of Industrial Chemistry, Wiley-VCH, Weinheim 2002. DOI:10.1002/14356007.a17 265

[53] Yu.A. Hizhnyi, S.G. Nedilko, V.P. Chornii, M.S. Slobodyanik, I.V. Zatovsky, K.V. Terebilenko, J. Alloys Comp. 614, 20 (2014)).

[54] M. Pizzoli, M. Scandola, G. Ceccorulli, Plast. Rubber Composit. Process. Appl. 16, 239 (1991)

[55] T.G. Rials, W.G. Glasser, J. Appl. Polym. Sci. 36, 749 (1988).

[56] P. Wojciechowski, J. Appl. Polym. Sci. 76, 837 (2000)).

[57] M.U. Belii, I.Ya. Kushnirenko, S.G. Nedilko, V.P. Sakun, J. Appl. Spectrosc. 48, 835 (1988).

[58] M.H. Brooker, D.E. Irish, Can. J. Chem. 49, 1289 (1971)).

[59] J.C. Fanning, Coord. Chem. Rev. 199, 159 (2000).

[60] Y.T. Kononenko, I.Ya. Kushnirenko, S.G. Nedilko, V.P. Sakun, J. Appl. Spectrosc. 42, 85 (1985). 